\title{
Articulation Compatibility in Eliciting Price Bids
}

\author{
ALEXANDER CHERNEV*
}

\begin{abstract}
Do consumers prefer auctions that allow them to place more precise bids to auctions that accept less precise bids? Can consumers accurately estimate their need for price-elicitation precision? This research addresses these questions by applying the notion of compatibility to the relationship between consumers' bidding price uncertainty and the precision implied by the price-elicitation task. Data from four experiments show that when consumers are uncertain about the optimal bidding price, decision tasks requiring elicitation of precise bids lead to lower decision confidence, and vice versa. It is further shown that consumers display stronger preference for high-precision auctions, even though such auctions are associated with less confident pricing decisions.
\end{abstract}

$\mathrm{M}$ ost of the extant consumer research has examined decision environments in which prices are readily available to buyers. In this context, typical research questions address issues such as how consumers evaluate, encode, and store the price information; how they infer missing price information; and how price information influences an option's perceived performance on nonprice attributes (Janiszewski and Lichtenstein 1999; Lichtenstein, Bloch, and Black 1988). This stream of research reflects the classic marketing paradigm in which options' prices are readily given to consumers who, in turn, evaluate the price information and act upon it either by buying or not buying the product.

The growth of interactive marketplaces has contributed to the increasing popularity of alternative pricing mechanisms in which prices are elicited by consumers instead of being set by managers. For example, online auctioneers such as eBay and Priceline offer consumers the opportunity to bid for commodity products such as airline tickets, hotel rooms, and car rentals. Price-bid articulation is also common in such areas as sales, trading, and negotiations. Unlike the traditional pricing, where the merchant sets the price and consumers respond by choosing to either purchase or not purchase the product, in the above scenarios consumers themselves set the price and the merchant chooses to either accept or reject their bid. Because the price-setting functions of the buyer are reversed in this scenario, it is referred to as reverse pricing. An important, yet often overlooked, as-

*Alexander Chernev is associate professor of marketing at Kellogg School of Management, Northwestern University, 2001 Sheridan Road, Evanston, IL 60208 (ach@northwestern.edu). The author thanks Pierre Chandon, Ryan Hamilton, Vincent Nijs, the editor, the associate editor, and the three anonymous reviewers for their advice and constructive comments.

Dawn Iacobucci served as editor and Stephen Nowlis served as associate editor for this article.

Electronically published October 10, 2006 pect of this buyer-driven pricing process is the precision with which consumers articulate their price bids. To illustrate, consider two auctions with different pricing formats, one allowing consumers to name their price with great precision (e.g., in dollars and cents) and another that accepts rounded bids only (e.g., in dollars only). Do consumers prefer the auction that allows more bid-articulating precision or do they opt for the less precise one? Which of these two auctions will lead to more confident pricing decisions? What factors moderate consumer preferences for either highprecision or low-precision auctions? In general, asking consumers to articulate their willingness to pay raises the question of how the precision of the price-articulation task influences consumers' decision processes.

The extant research in the area of auction pricing does not directly address the role of precision in eliciting price bids. Prior auction research has focused on such issues as the winner's curse (e.g., Ball, Bazerman, and Carroll 1991; Foreman and Murnighan 1996), bidders' pricing strategies (e.g., Sinha and Greenleaf 2000), and serach costs and competition (Lynch and Ariely 2000). The effect of scale precision on bid articulation has also been of marginal interest to the extant pricing research, which has focused primarily on consumers' perception of readily available prices and price ranges (e.g., Briesch et al. 1997; Janiszewski and Lichtenstein 1999; Winer 1986).

Building on the extant research, this article posits that consumers tend to display stronger preferences for priceelicitation auctions that require higher price-elicitation precision, even though such auctions tend to be associated with less confident pricing decisions. The implicit assumption here is that, when choosing among auctions, a rational consumer should choose the auction that is associated with the highest decision confidence and has the highest perceived likelihood of a successful bid outcome. In this context, the systematic preference for high-precision over low-precision auctions, despite the fact that high-precision auctions often 
lead to less confident decisions and lower expectation of a successful bid, can be viewed as an overestimation of consumers' need for precision. A more detailed analysis of the antecedents and consequences of this discrepancy between the buyers' stated price-precision preferences and the preferences derived from their post-decision behavior is offered in the following sections.

\section{THEORETICAL BACKGROUND}

Consumers' price-elicitation decisions can be viewed as a function of the constraints imposed by the price-elicitation task, such as the level of precision with which the desired price is to be specified. In this context, the focus of this research is on the consistency between consumers' priceprecision preferences when choosing among auctions and their price-precision preferences after having elicited a price in the context of the selected auction. To be more specific, the focus is on whether consumers can adequately estimate their need for price precision as reflected in the consistency of their selection of a price-elicitation task and their confidence in the decision stemming from the selected priceelicitation task.

Prior research suggests that, when choosing among options, consumers are likely to choose the one that imposes fewer constraints and offers the greatest decision flexibility (Reibstein, Youngblood, and Fromkin 1975; see also Brehm and Cohen 1959; Ratner, Kahn, and Kahneman 1999). It has also been argued that consumer preference for greater decision flexibility is a function of the desire to maintain options in the future and avoid the conflict of making a choice in the present (Simonson 1990). Thus, when choosing among tasks that vary in price precision, the decisionflexibility argument implies that consumers are likely to choose the auction that offers greater price-articulation precision because it avoids trade-offs and allows them to keep their options open. In fact, choosing a high-precision auction over a low-precision auction can be viewed as a trivial decision because it offers consumers the option to more precisely articulate their price without any apparent costs associated with this selection.

In contrast, when eliciting a price in the context of a task with a readily defined level of precision, consumers' decision processes are likely to be a function of the relationship between their uncertainty about the optimal bidding price and the precision implied by the price-elicitation task. In this research, this relationship is referred to as articulation compatibility, a derivation of the more general concept of decision compatibility, according to which the weighting of inputs is enhanced by their compatibility with the output (Fischer and Hawkins 1993; Tversky, Sattath, and Slovic 1988).

Building on the extant compatibility research, it is argued that consumers' bidding behavior is moderated by the degree of compatibility between their uncertainty about the optimal bidding price and the precision implied by the price-elicitation task. Thus, in cases where consumers are uncertain about the optimal bidding price, decision tasks requiring elicitation of precise price bids are likely to lead to lower decision confidence. This prediction is based on the notion that, when given a high-precision bidding task, consumers are faced with the difficult task of mapping their vague estimates of the optimal bidding price onto the precise bidding scale. Thus, a consumer who has no intuition about the underlying distribution of bidder and seller reservation prices and has no precise estimate of the optimal bidding price will be less confident in his/her pricing decision when asked to place a very precise bid than when asked to place a less precise bid.

The proposition that decision tasks requiring high priceelicitation precision will lead to less confident pricing decisions is consistent with the research on the role of precision and vagueness in representing uncertain information (see Wallsten [1990] for a review). Researchers in this area have shown that the decision-making process is best served when uncertainty is represented as precisely as possible yet not more precisely than warranted. In this context, it has been shown that the more vague is the individual's opinion, the less appropriate is a representation using unique probabilities (Budescu and Wallsten 1987; Wallsten et al. 1993).

The articulation compatibility argument is further consistent with the notion of graininess, which refers to the precision with which individuals communicate the degree of confidence they accord their judgments (Yaniv and Foster $1995,1997)$. To illustrate, an estimate of $\$ 8-\$ 10$ can be described as having higher graininess than the vaguer estimate of $\$ 4-\$ 14$. In this context, it has been shown that the vagueness or specificity of an estimate clearly depends on individuals' confidence in their knowledge, such that higher confidence levels lead to more specific estimates. The notion of price-elicitation precision used in this article is similar to that of graininess, with one main difference: while graininess is used to describe the impact of individuals' confidence on the precision of their estimates, priceelicitation precision reflects how precision influences individuals' decision confidence.

In general, this research argues that high-precision pricing tasks tend to be preferred to low-precision tasks, even though prices elicited in the context of high-precision tasks tend to be associated with lower decision confidence. Building on the above discussion, it is proposed that, when predicting their preferences, consumers tend to overestimate their actual need for price-elicitation precision. In particular, when given a choice between high-precision and lowprecision auctions, consumers will exhibit a preference for the high-precision auction, even though this auction is likely to be associated with less confident pricing decisions. This prediction can be summarized as follows:

H1: When choosing between price-elicitation tasks, consumers tend to overestimate their preference for price-elicitation precision, such that highprecision elicitation tasks are preferred to lowprecision tasks, even though prices elicited in the context of high-precision tasks are often associated with lower decision confidence. 
This prediction is tested in the following experiment.

\section{EXPERIMENT 1}

The goal of this experiment was to test the prediction that consumers who are uncertain about their bidding price tend to overstate their need for price-elicitation precision. The experimental paradigm involved asking respondents to choose between a high-precision and a low-precision auction and then comparing these stated preferences with the preferences derived from respondents' decision confidence ratings. A stronger preference for high-precision auctions associated with weaker confidence levels in choices from these auctions was then interpreted as indicative of an overestimation of the need for precision.

\section{Method}

Ninety-one Northwestern University undergraduates were recruited to participate in the experiment. They were told that the study involved testing a new online auction service, and they were presented with a scenario in which they had to acquire several products from BestBid-a fictitious auction Web site. Respondents were given the following instructions:

\footnotetext{
You have to indicate how much you are willing to pay for the product you would like to purchase. BestBid then searches for a retailer that is willing to sell the item at your price. You can bid only once for each item. BestBid will make the best effort to get the item at your price. BestBid will submit your bid along with those of other customers to its partner retailers, who will then decide on the lowest price to accept. Everyone whose bid is higher or equal to that price will receive the product at the stated price (which can be either equal to or higher than the lowest accepted price). If your bid is not accepted, you will have to buy the product at the regular price. Thus, the only reason to use a reverse price auction is to get a better price.
}

Respondents were then given a choice between a highprecision and a low-precision auction and were asked to indicate at which auction they would prefer to bid. Upon indicating their preference for one of the two auctions, respondents were given an unrelated filler task followed by a new auction in a different product category and were then asked to place their bid. Upon placing their bid, respondents were asked to rate their decision confidence ( $0=$ not confident; $100=$ very confident) and to rate the perceived likelihood of getting the item at the stated price $(0=$ very low; $100=$ very high). Finally, respondents were given a third auction problem that was similar to the second one except for the elicitation precision. Thus, respondents who were given the low-precision auction in the previous task were now given a high-precision auction, and vice versa.

To gain convergence of results across different elicitation procedures, this experiment employed two different price-elicitation tasks: generation and selection. In the pricegeneration task, consumers were explicitly asked to state the price they were willing to pay for the product under consideration, whereas in the selection task they had to select a price from a list. In particular, respondents in the pricegeneration scenario were asked to choose between an auction in which they had to name a price rounded to the nearest $\$ 10$ (low precision) and an auction in which they were asked to state their price in dollars and cents (high precision; see tasks A and B in the appendix). Respondents in the priceselection scenario had to choose between an auction offering a list of 10 prices and an auction offering a list of 90 prices. Price range was identical in both auctions; the key difference was the price-point density (see the appendix, tasks $\mathrm{C}$ and D).

Respondents were assigned to either the generation or the selection condition, and each respondent made three decisions: a choice between a high-precision and low-precision auction and two pricing decisions-one in a low-precision auction and one in a high-precision auction. The sequence in which the elicitation precision (high vs. low) manipulations were presented to respondents was counterbalanced to account for potential order effects. Each of the three decision scenarios was given in the context of a different product category, and the order in which product categories were assigned to experimental conditions was rotated across respondents.

The product categories used in this study were digital camera, iPod music player, and TiVo personal digital recorder. The description of these products included a brief overview accompanied by a picture. Respondents were also given the regular price for each product (the price at which it can be readily purchased), which was set to equal the highest price on the list used in the selection scenario. The regular price was included to make the auction more realistic and to make the price-generation and selection scenarios more comparable in terms of an available reference price for each product (Chernev 2003a).

The price-elicitation effects were tested in two contexts, using a price-generation and price-selection format. Based on a random assignment, there were 46 respondents in the generation condition and 45 in the selection condition. Respondents were tested either individually or in small groups, and upon completion of the experiment they were paid $\$ 5$ for participation.

\section{Results}

Respondents' tendency to overestimate their need for price-elicitation precision was examined by comparing the predicted preferences, revealed in their choice between a high-precision and a low-precision auction, with their actual preferences, revealed in the two pricing tasks following the choice. To measure respondents' actual preferences for price-elicitation precision, a binary measure was created to indicate whether a particular individual was more confident in a high-precision or low-precision price-elicitation task.

Of the 91 respondents, 17 indicated equal confidence in high-precision and low-precision auctions and were excluded from the analysis. The majority of the remaining 75 
respondents $(78.7 \%)$ selected the high-precision auction, while only $21.3 \%$ selected the low-precision auction. However, comparing the decision confidence of respondents across the high-precision and low-precision bidding tasks revealed a reverse pattern whereby the majority $(62.7 \%)$ of the respondents were more confident in their decisions when bidding in the lower precision auction and only $37.3 \%$ were more confident when bidding on the higher precision auction (fig. 1). The significance of this effect was tested using a model in which choice was given as a function of decision confidence and the nature of the decision task (generation vs. selection). The corresponding data analysis reveals that the difference between the predicted preferences and the displayed decision confidence was significant $\left(\chi^{2}(1)=\right.$ $29.83, p<.001)$ - a finding that is consistent with hypothesis 1.

The data reflecting respondents' estimation of the likelihood of success of their bid displayed a pattern similar to that of decision confidence. When choosing a price-elicitation task, $78.4 \%$ of the respondents selected the high-precision auction and only $21.6 \%$ selected the low-precision auction $(N=74)$. In contrast, $60.8 \%$ of the respondents indicated that they expected their low-precision bid to be more successful than their high-precision bid, and only $39.2 \%$ indicated that that they expected their high-precision bid to be more successful. This difference was significant $\left(\chi^{2}(1)=28.71\right.$, $p<.001$ ), lending additional support to hypothesis 1 .

Further insight into individual price-elicitation decisions can be obtained by examining the ratings of respondents' decision confidence and success likelihood (summarized in table 1). Analysis of the decision-confidence data shows that the mean averages in the low-precision generation $(M=$ 58.46) and low-precision selection tasks $(M=64.89)$ were higher than the mean averages for the high-precision generation and selection tasks, respectively $(M=55.67$ and $M=59.11$ ). The significance of these differences was examined by testing a model (repeated measures ANOVA) in which decision confidence was given as a function of elicitation precision (high vs. low), elicitation format (generation vs. selection), product category, presentation order, and all interactions. The corresponding analysis revealed a significant main effect of elicitation precision $(F(1,79)=$ $5.42, p<.05)$, whereas all interactions were nonsignificant $(F<1)$, indicating that this effect is consistent across both elicitation formats and across all design factors. The main effect of the elicitation format was significant $(F(1,79)=$ $3.99, p<.05)$, indicating that respondents appeared more confident when selecting than when generating their bids.

There was also a significant order effect such that respondents who were first given a high-precision task were, on average, less confident in their bids than those who were first given a low-precision task $(M=57.0$ vs. $M=61.9$; $F(1,79)=3.90, p<.05)$. This finding suggests that respondents' second bidding decisions might have been facilitated by their first bid, which served as a reference point and reduced the subjectively experienced bidding price uncertainty. To control for this, the impact of price-elicitation

\section{FIGURE 1}

THE DISPERSION OF STATED AND DERIVED PRECISIONELICITATION PREFERENCES (EXPERIMENT 1)

Choice share

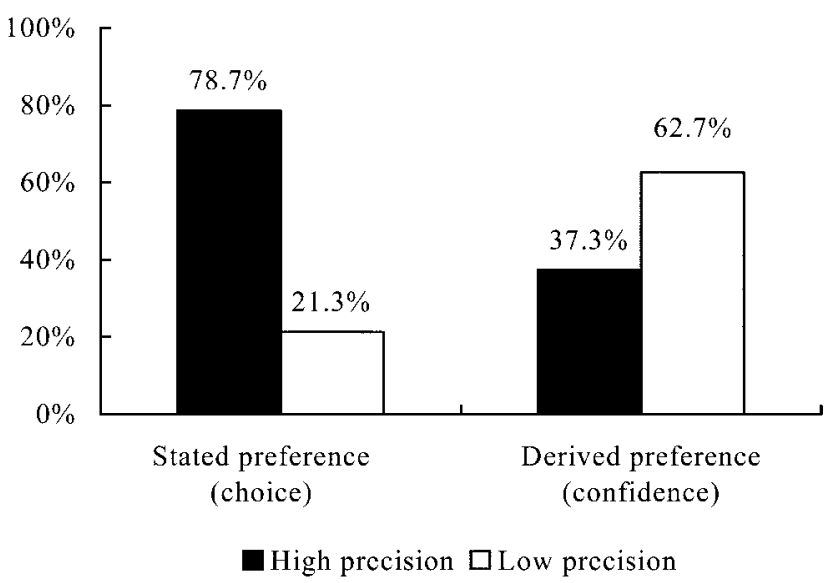

precision on decision confidence was also tested as a between-subject factor-by considering only the first pricing decision made by each individual. The data pattern resulting from such analysis was similar to the data reported above, showing a significant effect of price-elicitation precision on confidence $(F(1,79)=9.17, p<.01)$. Among the other effects, the only marginally significant factor was the decision task (selection vs. generation; $F(1,79)=3.43, p<.10$ ), although none of the interactions involving that factor was significant.

The success likelihood data displayed a similar pattern. The means in the low-precision generation $(M=53.74)$ and lowprecision selection conditions $(M=61.44)$ were higher than the means in the high-precision generation $(M=52.61)$ and high-precision selection conditions $(M=55.89)$. Analysis of these data shows that the main effect of elicitation precision was significant $(F(1,79)=3.93, p<.05)$. As in the case of decision confidence, there was a significant main effect of the decision task $(F(1,79)=4.32, p<.05)$ and a marginally significant order effect $(F(1,79)=3.27, p<.10)$; the other effects and interactions were nonsignificant. The betweensubject analysis replicated the decision confidence pattern, showing a significant main effect of elicitation precision $(F(1,79)=8.01, p<.01)$ and a marginally significant decision task effect $(F(1,79)=3.84, p<.10)$.

Overall, the ratings data show that respondents were more confident in their decisions and perceived these bids to have a higher likelihood of success when bidding in low-precision rather than high-precision auctions. These findings are consistent with the theoretical argument leading to hypothesis 1 , lending support for the experimental propositions.

\section{Discussion}

Hypothesis 1 argues that, when predicting their preferences, consumers are likely to overestimate their need 
TABLE 1

DECISION CONFIDENCE AND PREDICTED LIKELIHOOD OF BID SUCCESS AS A FUNCTION OF THE TYPE AND PRECISION OF THE BIDDING TASK (EXPERIMENT 1)

\begin{tabular}{|c|c|c|c|c|}
\hline & \multicolumn{2}{|c|}{ Decision confidence } & \multicolumn{2}{|c|}{ Success likelihood } \\
\hline & High-precision & Low-precision & High-precision & Low-precision \\
\hline Price-generation task & $\begin{array}{c}55.67 \\
(16.55)\end{array}$ & $\begin{array}{c}58.46 \\
(15.21)\end{array}$ & $\begin{array}{c}52.61 \\
(17.57)\end{array}$ & $\begin{array}{c}53.74 \\
(16.24)\end{array}$ \\
\hline Price-selection task & $\begin{array}{c}59.11 \\
(15.46)\end{array}$ & $\begin{array}{c}64.89 \\
(14.94)\end{array}$ & $\begin{array}{c}55.89 \\
(13.50)\end{array}$ & $\begin{array}{c}61.44 \\
(13.47)\end{array}$ \\
\hline
\end{tabular}

NOTE.-Total number of respondents $=91$; standard deviations are given in parentheses.

for price-elicitation precision. The data are consistent with this prediction, demonstrating that respondents were more likely to prefer the high-precision task even though higher precision pricing decisions were associated with lower decision confidence. The data also show a main effect of price-elicitation precision on decision confidence, whereby respondents who were given a high-precision price elicitation task were less confident in their decisions and had lower expectations regarding the likely success of their bid than respondents who were given a low-precision elicitation task. The convergence of decision confidence and success likelihood data, showing that respondents who selected the highprecision auction assigned lower probability of success to bids made in that auction, lends further support for the proposition that consumers overestimate their need for priceelicitation precision. The observed effects were consistent across the generation and selection tasks, demonstrating that these effects are robust to variations in the price-elicitation mode.

An alternative account for the observed decision confidence and success likelihood data is that respondents in the low-precision and high-precision conditions could have elicited different bids, which, in turn, could have had a direct effect on confidence and success likelihood. This possibility can be accounted for by comparing bids elicited by respondents in the high-precision and low-precision conditions. The analysis of these bids shows that respondents in the low-precision and the high-precision conditions placed bids that were not significantly different from one another $(M=276.6$ vs. $M=273.5 ; F(1,79)<1)$. This suggests that the observed differences in confidence and success likelihood ratings were not driven by differences in the elicited prices.

In general, respondents' tendency to overstate their need for price-elicitation precision was attributed to the degree of compatibility between consumers' uncertainty about the optimal bidding price and the precision implied by the priceelicitation task, such that for consumers who were uncertain about the optimal bidding price, the high-precision pricing task resulted in lower decision confidence. Following this line of reasoning, one could further argue that the decision compatibility argument must also be true for individuals with low levels of uncertainty in the optimal bidding price. Thus, low levels of price uncertainty should be more com- patible with higher (rather than lower) price-elicitation precision tasks. In this context, a further test of the proposition that the lower decision confidence associated with the highprecision task can be attributed to articulation compatibility involves explicitly examining decision confidence as a function of the compatibility of individuals' preference uncertainty and the precision implied by the price-elicitation task. In particular, decisions in which the precision of a consumer's reference price is incompatible with the precision imposed by the decision task (e.g., an ambiguous bidding price and a high-precision elicitation task) are likely to be associated with lower confidence relative to decisions in which the precision of the expected bidding price matches the precision implied by the price-elicitation task (e.g., an articulated bidding price and a high-precision elicitation task).

This prediction can be summarized in the following hypothesis:

H2: When articulating price bids, consumer decision processes are a function of the compatibility between the degree of uncertainty about the optimal bidding price and the precision implied by the price-elicitation task. In particular, consumers with high bidding price uncertainty will be more confident in imprecise bids than precise bids, whereas for consumers with low bidding price uncertainty this effect is reversed, leading to greater confidence in precise bids rather than imprecise bids.

This hypothesis is tested in the following experiment.

\section{EXPERIMENT 2}

The goal of this experiment was to test the prediction advanced in hypothesis 2 that the compatibility between consumers' uncertainty about the optimal bidding price and the precision of the price-articulation task is likely to influence their bidding preferences.

\section{Method}

Respondents, 101 Northwestern University undergraduates, were presented with a hypothetical scenario in which they had to acquire several products from the auction Web 
site BestBid, as described in the first experiment. They were asked to make four pricing decisions, one in each of four different product categories: CD player, TiVo recorder, MP3 player, and digital camera. As in the first experiment, there were two price elicitation tasks: price generation and price selection. Both tasks were similar to those used in the first experiment except for the product descriptions and the listed prices, which were evenly distributed with ranges as follows: CD player, \$149-\$329; digital camera, \$201-\$379; TiVo, \$101-\$279; and MP3 player, \$121-\$299.

Respondents' bidding-price uncertainty was manipulated by providing some of the respondents with information about the optimal (the lowest successful) bid for the same item in an earlier auction. Respondents were also told that bidding prices varied from auction to auction and that the prior bidding history information was provided to serve as a general guideline rather than as an indication of the exact amount of the winning bid in the following auction.

Respondents were randomly assigned to one of the two bidding-price uncertainty conditions, such that there were 50 respondents in the high-uncertainty condition and 51 in the low-uncertainty condition. Each respondent made four decisions: two high-precision and two low-precision decisions, which were given in either a price-generation or a price-selection context. The order in which the elicitation precision (high vs. low) and the elicitation task (generate vs. select) manipulations were presented was counterbalanced across respondents to account for potential order effects.

Upon completing each of the product-specific price selection tasks, respondents were asked to indicate their decision confidence $(0=$ not confident; $100=$ very confident), as well as the (perceived) likelihood of getting the item at the stated price $(0=$ very low; $100=$ very high $)$. Respondents were tested either individually or in small groups, and upon completion of the experiment they were paid $\$ 5$ for participation.

\section{Results}

Each of the 101 respondents made four decisions, yielding 404 observations in total. The data show that respondents' decisions were a function of the bidding-price uncertainty and the precision required by the price-elicitation task. Thus, for respondents in the high-uncertainty condition, the decision confidence mean for the low-precision task $(M=$ 65.02) was higher than the mean for the high-precision task $(M=57.12)$. In contrast, for respondents in the lowuncertainty condition, the effect was reversed, such that the decision confidence mean for the low-precision task ( $M=61.27)$ was lower than the mean for the high-precision task $(M=66.24)$. The direction of these effects is consistent with the experimental predictions advanced in hypothesis 2 .

The significance of these data was examined by testing a model (repeated-measures ANOVA) in which decision confidence was given as a function of bidding-price uncertainty (high vs. low), elicitation precision (high vs. low), elicitation task (generation vs. selection), product category, and all interactions. The analysis reveals a significant interaction between price uncertainty and elicitation precision $(F(1,279)=12.50, p<.001)$-a finding consistent with the predictions made by hypothesis 2 . All other interactions were nonsignificant $(F<1)$, indicating that this effect is consistent across both decision tasks (generation and selection) and across product categories.

Further analysis reveals that, for respondents in the highuncertainty condition, the impact of the precision of the price-elicitation task was significant $(M=65.02$ vs. $M=$ $57.12 ; F(1,279)=9.33, p<.005) — \mathrm{a}$ finding supporting the notion that, in the presence of bidding-price uncertainty, decision tasks requiring elicitation of precise price bids could lead to lower decision confidence than tasks requiring less precise bids. The data further show that, for respondents in the low-uncertainty condition, this impact was significant as well $(M=61.27$ vs. $M=66.24 ; F(1,279)=3.76$, $p<.05)$. This finding is consistent with the notion that, when the bidding-price uncertainty is low, decision tasks requiring elicitation of precise price bids could lead to higher decision confidence than tasks requiring less precise bids.

The success likelihood data followed a similar pattern. Respondents in the high-uncertainty condition expressed a greater likelihood of success in the bidding process when given a low-precision than when given a high-precision pricing task $(M=59.03$ vs. $M=46.52)$. In contrast, for respondents in the low-uncertainty condition, the effect was reversed, such that the mean rating of the perceived success likelihood for the low-precision task was lower than the mean for the high-precision task $(M=54.89$ vs. $M=$ 55.98). Analysis of these data shows that the interaction effect was significant $(F(1,279)=14.36, p<.001)$, a finding consistent with hypothesis 2 . All interactions were nonsignificant $(F<1)$, indicating that this effect is consistent across both decision tasks (generation and selection) and across product categories.

\section{Discussion}

The data furnished by this experiment show that, when articulating price bids, consumer decision processes are a function of the compatibility between the degree of uncertainty about the optimal bidding price and the precision implied by the price-elicitation task, such that respondents who were less certain about the optimal bidding price were also less confident in the context of a high-precision than a low-precision price-elicitation task. In contrast, those more certain about the optimal bidding price were more confident when given a high-precision than a low-precision priceelicitation task. These findings lend further support to the notion that, under preference uncertainty, consumers tend to underestimate the increased task difficulty imposed by the greater price-elicitation precision and, as a result, tend to overstate their need for flexibility when choosing among auctions that vary in price-elicitation precision.

The finding that consumers tend to overestimate their need for precision naturally raises the question of whether it is 
possible to "correct" this overestimation (e.g., Fischhoff 1982; Gilbert 2002; Petty and Wegener 1993). It was theorized that this overestimation is caused by the fact that, when consumers are asked to choose between auctions that vary in price-elicitation precision, their focus is primarily on maximizing their future options. In this context, the drawbacks of choosing the higher precision auction should be less salient to consumers when choosing between auctions than when placing an actual bid. Consequently, one strategy to "correct" the overestimation of the need for precision is to shift the focus of the decision task in a way that makes the articulation incompatibility more salient.

One approach to shifting the decision focus from the auction-choice task to the pricing task is to vary respondents' decision accountability. Such manipulation is consistent with prior research (Chernev 2006; Lerner and Tetlock 1999; Simonson and Nye 1992; Tetlock 1983a), which documents that accountability is an important determinant of what people think (i.e., their beliefs and preferences), as well as how they think (i.e., decision strategies and reasoning underlying those beliefs and preferences). In particular, accountability has been shown to significantly reduce a number of decision biases, such as primacy effects in impression formation (Tetlock 1983b), overattribution effects (Tetlock 1985), and overconfidence effects (Tetlock and Kim 1987).

In this context, this research argues that asking consumers to justify either their choice of an auction or their choice of price can influence their preferences for price-elicitation precision in a way that reduces the overestimation effect reported in the first two experiments. Thus, when asked to justify their choice of an auction, consumers are likely to find it easier to justify the option that offers the greater priceelicitation precision. In contrast, when asked to justify the elicited price, consumers might find it easier to justify a bid that is less precise. Indeed, the larger the set of possible prices, the more difficult it should be to justify any particular price, since selecting a particular price also implies rejecting the other possible prices - a task more easily accomplished in the context of a smaller rather than a larger set of possible prices (Festinger 1964). It is, therefore, predicted that accountability is likely to reduce consumers' tendency to overestimate their need for price-elicitation precision but only in cases when the focus of accountability is on the outcome of the price-elicitation process. This prediction can be stated more formally as follows:

H3: The preference for price-elicitation precision is a function of decision accountability. In particular, the preference for precision will be greater when consumers expect to have to justify their choice of an auction than when they expect to have to justify their price bids from the selected auction.

This hypothesis is tested in the next experiment.

\section{EXPERIMENT 3}

The goal of this experiment was to examine the impact of the need for justification on consumer preference for price-elicitation precision. The need for justification was manipulated by giving respondents a choice between a highprecision and a low-precision auction, such that some respondents were informed that they would be asked to justify their choice of an auction and others that they would be asked to justify the price elicited in the selected auction.

\section{Method}

Respondents, 228 Northwestern University undergraduates, were given an overview of the bidding task, which was the same as that in the first experiment, and were asked to imagine that they were buying an MP3 player regularly priced at \$299. Respondents were also given a choice of two auctions: a high-precision auction and a low-precision auction. As in the first experiment, the research hypothesis was tested in the context of a generation task and a selection task. Bidding options were the same as in the first experiment (see the appendix), except for the price range defined by the selection task (\$121-\$299).

Respondents were randomly assigned to one of the three experimental conditions and were asked to indicate which of the two options they would prefer. Some of the respondents were told they might be asked to justify their choice of an auction (choice-justification condition). Others were told that they might be asked to justify their price (pricejustification condition). Thus, the key difference between these two conditions was the focus of justification-either the choice of an auction or the actual bid. Finally, the remainder of the respondents were not provided with any justification information (control condition).

\section{Results}

Based on a random assignment, there were 73 respondents in the choice-justification condition, 66 in the pricejustification condition, and 69 in the no-justification condition. Each respondent was given a single decision task, which yielded 208 observations in total. The data pattern indicates that respondents in the choice-justification condition were the most likely to select the high-precision auction, whereas those in the price-justification condition were the least likely to select the high-precision auction. In particular, $90.4 \%$ of respondents in the choice-justification condition selected the high-precision auction, compared to $84.1 \%$ in the control condition and $59.1 \%$ in the pricejustification condition.

The significance of these data was tested using a model in which the respondents' auction preferences were given as a function of justification and elicitation tasks and their interaction. The corresponding analysis shows a significant effect of the justification task $\left(\chi^{2}(2)=19.75, p<.001\right)$, whereas both the elicitation task and the interaction effects were nonsignificant $\left(\chi^{2}<1\right)$. For each of the two levels of the elicitation task (generation vs. selection), the effect of accountability was significant as well $\left(\chi^{2}(2)=10.00, p<\right.$ .01 for the selection task and $\chi^{2}(2)=9.79, p<.01$ for the 
generation task) — a finding that is consistent with hypothesis 3.

More important, the difference in respondents' priceprecision preferences in the two justification conditions was significant $\left(\chi^{2}(1)=15.92, p<.001\right)$, lending further support to hypothesis 3. Finally, the difference between respondents in the no-justification and price-justification conditions was also significant $\left(\chi^{2}(1)=9.82, p<.005\right)$, whereas the difference between the no-justification and choice-justification conditions was nonsignificant $\left(\chi^{2}=\right.$ 1.29). Overall, these data show that varying the focus of the justification task (choice of an auction type vs. price-related outcome) moderates the perceived need for precision and that asking respondents to justify their price bids might actually lower their need for price-elicitation precision.

\section{Discussion}

The data reported in this experiment are consistent with the prediction that the need for future price-elicitation precision is a function of decision focus. The data show that the preference for price-elicitation precision was greater for respondents who expected to justify their choice between auctions with different levels of price-elicitation precision than for respondents who expected to justify their articulated prices. In particular, asking respondents to justify their articulated price bids resulted in a significant decrease in preference for the high-precision auction, whereas asking them to justify their choice of either a high-precision or lowprecision auction did not significantly increase their preference for the high-precision auction. The asymmetric nature of the observed effect can be attributed to ceiling effects resulting from the strong preference for the high-precision auction.

It was argued that this overestimation of the need for precision stems from the fact that, when consumers are asked to choose between auctions that vary in price-elicitation precision, their focus is primarily on maximizing their future options. Experiment 3 tested this prediction by shifting the focus of decision accountability from the auction-choice task to the price-articulation task. An alternative strategy to test this prediction is to make the difficulty of the pricearticulation task more salient without explicitly asking respondents to justify their decisions. One approach is to give respondents a learning task that highlights the difficulty of the price-articulation task. Consequently, if articulation incompatibility is contributing to the overestimation of the need for precision, then manipulating the salience of the pricing task is likely to make the potential articulation incompatibility more transparent to consumers. This prediction can be summarized as follows:

H4: The preference for price-elicitation precision is a function of the salience of the perceived difficulty of the price-articulation task. In particular, the preference for low-precision auctions will be greater when the difficulty of the price-articulation task is more salient.
This prediction is tested in the following experiment.

\section{EXPERIMENT 4}

The goal of experiment 4 was to test the proposition that overestimation of the need for precision is moderated by the perceived difficulty of the price-articulation task. In this experiment the salience of the pricing task was manipulated by introducing an initial learning task that was similar to the main price-articulation task and involved either a lowprecision or a high-precision price articulation. The logic for this manipulation is that priming respondents with a high-precision task will make the price-articulation uncertainty more pronounced. As a result, when making subsequent decisions, respondents will be aware of the difficulty of the high-precision elicitation task, and, when given a choice, they will be less likely to select the high-precision auction.

\section{Method}

One hundred and sixty-two Northwestern University undergraduates were randomly assigned to either the highuncertainty or low-uncertainty condition. Respondents were given an overview of the bidding task (which was the same as in the first experiment) and were asked to imagine that they had to buy a digital camera regularly priced at \$299. Next, they were asked to state the amount that they were willing to bid for the camera. Respondents in the highuncertainty condition were asked to select a price from a set of 90 prices (see the appendix, task D, price range: \$121-\$299) or, alternatively, to name the precise price they were willing to pay for the camera (see the appendix, task $\mathrm{B}$, price range: \$121-\$299). In contrast, respondents in the low-uncertainty condition were asked to select a price from a set of 10 prices (see the appendix, task C) or, alternatively, to name the price that they were willing to pay, rounded to the next $\$ 10$ (see the appendix, task A). As a manipulation check, respondents were also asked to indicate their confidence in the stated price (three-point scale: not confident, somewhat confident, and very confident). Similar priming tasks have been successfully used in prior research (Chernev 2006; Gollwitzer, Heckhausen, and Ratajczak 1990; Kelley and Lindsay 1993).

Following the learning task, respondents were asked to bid for a different digital camera priced at $\$ 379$ and were given a choice of two auctions: one with a high-precision and the other with a low-precision articulation scale. Respondents were then asked to choose one of these auctions. The nature of the elicitation task (generation vs. selection) was consistent across the priming and the main tasks: respondents asked to generate a price in the learning task were subsequently given a choice between two generation-based auctions, whereas those given a selection task were asked to choose between two selection-based auctions. Respondents were tested either individually or in small groups and upon completion of the experiment were paid $\$ 5$ for participation. 


\section{Results}

Seventy-nine of the 162 respondents were assigned to the low-uncertainty condition, and the remaining 83 respondents were assigned to the high-uncertainty condition. The data show that respondents in the high-uncertainty condition were less likely to select the high-precision auction than those in the low-uncertainty condition. This pattern was consistent for both generation and selection scenarios. Thus, in the price-generation condition, only $42.9 \%$ of the respondents in the high-uncertainty scenario $(N=42)$ chose the high-precision auction, compared to $61.5 \%$ of those in the low-uncertainty scenario $(N=39)$. Similarly, in the priceselection condition, $51.2 \%$ of respondents primed with a high-uncertainty task $(N=41)$ indicated a preference for the high-precision auction, compared to $70 \%$ of respondents $(N=40)$ who were primed with a low-uncertainty task.

The significance of these data was tested using a model in which respondents' choice of an auction was given as a function of the nature of bidding price uncertainty (high vs. low), the elicitation task (generation vs. selection), and their interaction. The data analysis shows a significant main effect of the priming task $\left(\chi^{2}(1)=5.74, p<.05\right)$, whereas the task $\left(\chi^{2}(1)=1.21, p>.20\right)$ and the interaction effects $\left(\chi^{2}<1\right)$ were nonsignificant, indicating that the observed effect was consistent across the generation and selection tasks. These data are consistent with predictions advanced by hypothesis 4 .

\section{Discussion}

The data reported in this experiment support the proposition that the need for price-elicitation precision is a function of bidding price uncertainty. Respondents who were given a high-precision priming task that made the pricearticulation task salient were less likely to opt for the auction with higher price-elicitation precision than those who were initially given the low-precision task. Combined with the results from experiment 3 , these data are consistent with the notion that making the price-elicitation task more salient tends to lower consumer preference for high-precision price articulation tasks.

\section{GENERAL DISCUSSION}

The research presented in this article demonstrates that, when choosing among auctions, consumers tend to display stronger preferences for price-elicitation tasks that require higher price precision, even though such auctions tend to be associated with less confident decisions (experiment 1). To account for the discrepancy between buyers' stated auction preferences and their preferences derived from postdecision confidence, this research applies the notion of compatibility to the relationship between the individual's bidding price uncertainty and the precision implied by the price-elicitation task.

In this context, it is shown that consumers' confidence in their price bids and the perceived likelihood of these bids being successful is a function of the compatibility of their uncertainty about the optimal bidding price and the degree of precision offered by the price-elicitation task. Thus, for consumers uncertain about the optimal bidding price, decision tasks requiring elicitation of precise bids resulted in lower decision confidence; for consumers more certain about the optimal bidding price, high price-elicitation precision resulted in more confident decisions (experiment 2).

This research further identifies two factors that are likely to moderate the articulation compatibility effect: decision accountability and the perceived difficulty of the pricearticulation task. Thus, it is shown that the preference for price-elicitation precision was a function of decision accountability (experiment 3 ). In particular, the preference for precision was stronger when consumers expected to have to justify their choice of an auction than when they expected to have to justify their prices. The preference for priceelicitation precision was also a function of the salience of the perceived difficulty of the price-articulation task, such that the preference for low-precision auctions was greater when the difficulty of the price-articulation task was more salient (experiment 4).

From a theoretical standpoint, this research adds a new dimension to the understanding of the compatibility principle and its impact on choice. Prior research applied the compatibility principle to the relationship between the attribute and response scales (Slovic, Griffin, and Tversky 1990; Tversky et al. 1988), as well as to the relationship of the nature of the decision task (e.g., quantitative vs. qualitative) and the type of decision strategy evoked (Fischer and Hawkins 1993). The notion of compatibility has been further applied to the relationship between the nature of the choice task and the type of attributes describing choice alternatives (Nowlis and Simonson 1997), as well as to the relationship between the decision goals and the nature of the choice task (Fischer et al. 1999). Building on this research, this article applies the notion of compatibility to the relationship between the degree to which individuals have articulated pricebased preferences (reflected in their uncertainty in the optimal bidding price) and the nature of the decision task (reflected in the precision of the price-elicitation scale). In this context, the articulation compatibility principle advanced in this research offers a new dimension to the understanding of the role of compatibility in consumer decision processes.

This research further contributes to the accountability literature (Lerner and Tetlock 1999; Simonson and Nye 1992; Tetlock 1983a) by demonstrating that changing the focus of accountability can influence consumer decision processes. Building on prior findings, this research demonstrates that the impact of accountability on decision biases is a function of the decision focus and, in particular, whether the focus is on justifying the choice among different decision tasks or on justifying the outcome of a readily given task. In this context, our findings suggest that by varying the reference point one could influence the impact of accountability on consumer decision processes. 
An interesting question raised by this research concerns the relatively robust consumer preference for more precise options. Indeed, even though experiments 3 and 4 identified factors that are likely to influence this preference, the psychological underpinning of consumer preferences for more precise options is subject to multiple interpretations. In this context, further research needs to explore how consumer intuitions about price-elicitation precision influence consumer decision processes and how these theories are influenced by the correction processes reported in this article.

Conceptually, the theory advanced in this article can be linked to the findings on the impact of preference uncertainty on consumer choice among assortments (Chernev 2003b;
Iyengar and Lepper 2000; Sood, Rottenstreich, and Brenner 2004). Similar to overestimating their need for elicitation precision when articulating price bids, consumers tend to overestimate their need for decision flexibility when choosing among assortments. In this context, prior research has demonstrated that, when choosing among assortments, consumers opt for the variety offered by larger assortments; however, consumers often are less confident in choices made from larger rather than from smaller assortments (Chernev 2006). Integrating these articulation compatibility effects when choosing an assortment and when eliciting price bids with a more general conceptualization of how consumers manage their need for decision flexibility is a promising area for further research. 


\section{APPENDIX \\ AN ILLUSTRATION OF DIFFERENT PRICE-ARTICULATION TASKS}

\section{A. Low-precision generation task}

Please write down the price you are willing to bid for this item.

$$
\text { S__ (rounded to the nearest } \$ 10 \text { ) }
$$

\section{B. High-precision generation task}

Please write down the price you are willing to bid for this item.

$$
\begin{aligned}
& \text { \$ } \\
& \text { [Dollars] [Cents] }
\end{aligned}
$$

\section{Low-precision selection task}

Please select the price you are willing to bid for this item

$\begin{array}{lllll}\square \$ 199 & \square \$ 239 & \square \$ 279 & \sqsupset \$ 319 & \sqsubset \$ 359 \\ \square \$ 219 & \square \$ 259 & \square \$ 299 & \sqsupset \$ 339 & \sqsubset \$ 379\end{array}$

\begin{tabular}{|c|c|c|c|c|c|c|c|c|c|}
\hline$\$$ & $\$$ & & & & & & & & \\
\hline & $\llcorner \$ 223$ & $\sqcup \$ 225$ & $\downarrow \$ 227$ & $\downarrow \$ 229$ & $\llcorner \$ 231$ & $\sqcup \$ 233$ & $\sqcup \$ 235$ & & $\llcorner \$ 239$ \\
\hline & $\sqsubset \$ 243$ & $\square$ \$245 & $\sqsupset \$ 247$ & $\sqsupset \$ 249$ & $\sqsubset \$ 251$ & $\square \$ 253$ & $\square \$ 255$ & 257 & $\sqsubset \$ 259$ \\
\hline & $\sqsubset \$ 263$ & 65 & $\sqsupset \$ 267$ & 269 & $\sqsubset \$ 271$ & 73 & 275 & & $\$ 279$ \\
\hline & $\sqsubset \$ 283$ & $\square \$ 285$ & $\sqsupset \$ 287$ & $\neg \$ 289$ & $\sqsubset \$ 291$ & $\square \$ 293$ & 295 & $\sqsupset \$ 297$ & $\sqsubset \$ 299$ \\
\hline & | $\$ 303$ & | | \$305 & $\mid \$ 307$ & & | \$311 & $\$ 313$ & & | \$317 & $\$ 319$ \\
\hline & Г $\$ 323$ & $\$ 325$ & $7 \$ 327$ & & $\$ 331$ & & & & \\
\hline & & & & & & & & & \\
\hline & $\$ 363$ & | \$365 & $\$ 367$ & $\$ 369$ & $\$ 371$ & $\$ 373$ & $\$ 375$ & | \$377 & $\$ 379$ \\
\hline
\end{tabular}

\section{High-precision selection task}

Please select the price you are willing to bid for this item: 


\section{REFERENCES}

Ball, Sheryl B., Max H. Bazerman, and John S. Carroll (1991), "An Evaluation of Learning in the Bilateral Winner's Curse," Organizational Behavior and Human Decision Processes, 48 (1), 1-22.

Brehm, Jack W. and Arthur R. Cohen (1959), "Reevaluation of Choice Alternatives as a Function of Their Number and Qualitative Similarity," Journal of Abnormal and Social Psychology, 58, 373-78.

Briesch, Richard A., Lakshman Krishnamurthi, Tridib Mazumdar, and S. P. Raj (1997), "A Comparative Analysis of Reference Price Models," Journal of Consumer Research, 24 (September), 202-14.

Budescu, David V. and Thomas S. Wallsten (1987), "Subjective Estimation of Precise and Vague Uncertainties," in Judgmental Forecasting, ed. George Wright and Peter Ayton, New York: Wiley, 63-82.

Chernev, Alexander (2003a), "Reverse Pricing and Online Price Elicitation Strategies in Consumer Choice," Journal of Consumer Psychology, 13 (1-2), 51-62.

- (2003b), "When More Is Less and Less Is More: The Role of Ideal Point Availability and Assortment in Consumer Choice," Journal of Consumer Research, 30 (September), $170-83$.

- (2006), "Decision Focus and Consumer Choice among Assortments," Journal of Consumer Research, 33 (June), $50-59$.

Festinger, Leon (1964), Conflict, Decision, and Dissonance, Stanford, CA: Stanford University Press.

Fischer, Gregory W., Ziv Carmon, Dan Ariely, and Gal Zauberman (1999), "Goal-Based Construction of Preferences: Task Goals and the Prominence Effect," Management Science, 45 (August), 1057-75.

Fischer, Gregory W. and Scott A. Hawkins (1993), "Strategy Compatibility, Scale Compatibility, and the Prominence Effect," Journal of Experimental Psychology: Human Perception and Performance, 19 (June), 580-97.

Fischhoff, Baruch (1982), "Debiasing," in Judgment under Uncertainty, ed. Daniel Kahneman, Paul Slovic, and Amos Tversky, Cambridge: Cambridge University Press, 422-44.

Foreman, Peter and J. Murnighan (1996), "Learning to Avoid the Winner's Curse," Organizational Behavior and Human Decision Processes, 67 (2), 170-80.

Gilbert, Daniel T. (2002), "Inferential Correction," in Heuristics and Biases: The Psychology of Intuitive Judgment, ed. Thomas Gilovich, Dale W. Griffin, and Daniel Kahneman, Cambridge: Cambridge University Press, 167-84.

Gollwitzer, Peter M., Heinz Heckhausen, and Heike Ratajczak (1990), "From Weighing to Willing: Approaching a Change Decision through Pre- or Postdecisional Mentation," Organizational Behavior and Human Decision Processes, 45 (1), 41-65.

Iyengar, Sheena S. and Mark R. Lepper (2000), "When Choice Is Demotivating: Can One Desire Too Much of a Good Thing?" Journal of Personality and Social Psychology, 79 (6), 995-1006.

Janiszewski, Chris and Donald R. Lichtenstein (1999), "A Range Theory Account of Price Perception," Journal of Consumer Research, 25 (March), 353-69.

Kelley, Colleen M. and D. Stephen Lindsay (1993), "Remembering Mistaken for Knowing: Ease of Retrieval as a Basis for Con- fidence in Answers to General Knowledge Questions," Journal of Memory and Language, 32 (1), 1-24.

Lerner, Jennifer S. and Philip E. Tetlock (1999), "Accounting for the Effects of Accountability," Psychological Bulletin, 125 (2), 255-75.

Lichtenstein, Donald R., Peter H. Bloch, and William C. Black (1988), "Correlates of Price Acceptability," Journal of Consumer Research, 15 (September), 243-52.

Lynch, John G. and Dan Ariely (2000), "Wine Online: Search Costs Affect Competition on Price, Quality, and Distribution," Marketing Science, 19 (1), 83-103.

Nowlis, Stephen M. and Itamar Simonson (1997), “Attribute-Task Compatibility as a Determinant of Consumer Preference Reversals," Journal of Marketing Research, 34 (May), 205-18.

Petty, Richard E. and Duane T. Wegener (1993), "Flexible Correction Processes in Social Judgment: Correcting for ContextInduced Contrast," Journal of Experimental Social Psychology, 29 (2), 137-65.

Ratner, Rebecca K., Barbara E. Kahn, and Daniel Kahneman (1999), "Choosing Less-Preferred Experiences for the Sake of Variety," Journal of Consumer Research, 26 (June), 1-15.

Reibstein, David J., Stuart A. Youngblood, and Howard L. Fromkin (1975), "Number of Choices and Perceived Decision Freedom as a Determinant of Satisfaction and Consumer Behavior," Journal of Applied Psychology, 60 (4), 434-37.

Simonson, Itamar (1990), "The Effect of Purchase Quantity and Timing on Variety-Seeking Behavior," Journal of Marketing Research, 27 (May), 150-62.

Simonson, Itamar and Peter Nye (1992), "The Effect of Accountability on Susceptibility to Decision Errors," Organizational Behavior and Human Decision Processes, 51 (3), 416-46.

Sinha, Atanu R. and Eric A. Greenleaf (2000), "The Impact of Discrete Bidding and Bidder Aggressiveness on Sellers' Strategies in Open English Auctions: Reserves and Covert Shilling," Marketing Science, 19 (3), 244-65.

Slovic, Paul, Dale Griffin, and Amos Tversky (1990), "Compatibility Effects in Judgment and Choice," in Insights in Decision Making: A Tribute to Hillel J. Einhorn, ed. Robin M. Hogarth, Chicago: University of Chicago Press, 5-27.

Sood, Sanjay, Yuval Rottenstreich, and Lyle Brenner (2004), "On Decisions That Lead to Decisions: Direct and Derived Evaluations of Preference," Journal of Consumer Research, 31 (June), 17-25.

Tetlock, Philip E. (1983a), “Accountability and Complexity of Thought," Journal of Personality and Social Psychology, 45 (1), 74-83.

(1983b), "Accountability and the Perseverance of First Impressions," Social Psychology Quarterly, 46 (4), 285-92. - (1985), "Accountability: A Social Check on the Fundamental Attribution Error," Social Psychology Quarterly, 48 (3), 227-36.

Tetlock, Philip E. and Jae I. Kim (1987), “Accountability and Judgment Processes in a Personality Prediction Task," Journal of Personality and Social Psychology, 52 (4), 700-709.

Tversky, Amos, Shmuel Sattath, and Paul Slovic (1988), "Contingent Weighting in Judgment and Choice," Psychological Review, 95 (July), 371-84.

Wallsten, Thomas S. (1990), "The Costs and Benefits of Vague Information," in Insights in Decision Making: A Tribute to Hillel J. Einhorn, ed. Robin M. Hogarth, Chicago: University of Chicago Press, 28-43.

Wallsten, Thomas S., David V. Budescu, Rami Zwick, and Steven M. Kemp (1993), "Preferences and Reasons for Communi- 
cating Probabilistic Information in Verbal or Numerical Terms," Bulletin of the Psychonomic Society, 31 (2), 135-38. Winer, Russell S. (1986), "A Reference Price Model of Brand Choice for Frequently Purchased Products," Journal of Consumer Research, 13 (September), 250-56.

Yaniv, Ilan and Dean P. Foster (1995), "Graininess of Judgment under Uncertainty: An Accuracy-Informativeness Trade-Off," Journal of Experimental Psychology: General, 124 (4), 424-32.

(1997), "Precision and Accuracy of Judgemental Estimation," Journal of Behavioral Decision Making, 10 (1), $21-32$. 